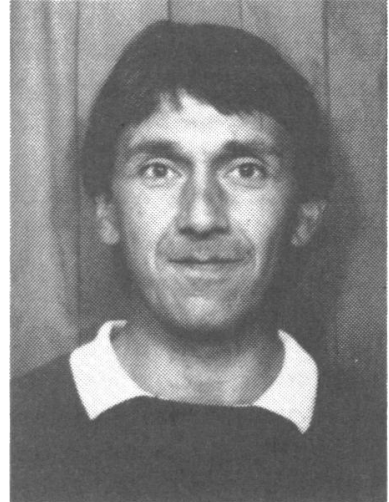

C. P. Hardy

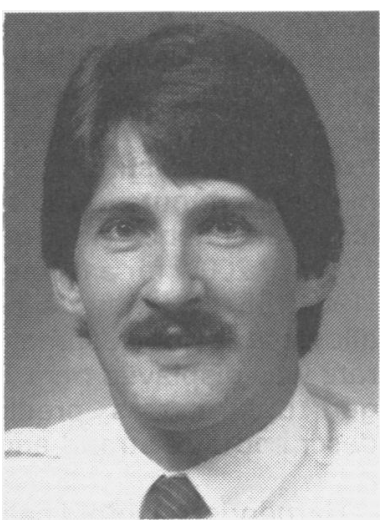

R. G. Eston

\title{
AEROBIC FITNESS OF ANGLO-SAXON AND INDIAN STUDENTS
}

\author{
C. P. HARDY, BEd, MEd* and R. G. ESTON, BEd, MEd, DPE** \\ *West Bromwich College of Commerce and Technology, West Midlands \\ **School of Physical Education, Liverpool University, PO Box 147, L69 3BX
}

\begin{abstract}
The purpose of this study was to compare the aerobic fitness of two groups of male college students: 32 Anglo-Saxon males (age range 16-18 years) with 27 Indian males, born in England, (age range 16-23 years), none of whom was highly active in any particular sport. Maximal oxygen uptake was estimated by submaximal test on a cycle ergometer and percent body fat was assessed by skinfold calipers. The Anglo-Saxon group had higher absolute and relative maximal oxygen consumption values and higher body weight. There was no difference in percent fat between the two groups. Strength data were also provided for descriptive purposes.
\end{abstract}

\section{INTRODUCTION}

Research has indicated that indigenous populations may differ in their ability to undertake endurance work (Verma et al, 1979). This is demonstrated by the wide range in maximal oxygen uptake values between population samples. It is probable that the endurance fitness of a population is influenced by a number of factors, including the climate, geographical relief, medical services, education services, recreation facilities, level of nutrition, and the incidence of acute and chronic diseases. Exposure to such influences over successive generations may well produce distinct differences of fitness levels based on genetic transmission.

Fox and Mathews (1981) have recognised that certain physiological and functional capacities are to a large extent determined by genetic limitations. They stated that even with the best possible training programme, the improvement in functional capabilities will ultimately be limited by genetic potential. Widely quoted research involving monozygous (identical) and dizygous (fraternal) twins has indicated that maximal oxygen uptake is determined predominantly by inheritance (Klissouras, 1971; Klissouras et al, 1973). Indeed Åstrand and Rodahl (1977) have indicated that since regular training can, in most cases, increase the maximal oxygen uptake by not more than 10 to 20 percent, it is evident that natural endowment is the most important factor determining the individual's maximum.

Verma et al (1979) noted wide differences in mean maximal oxygen uptake scores in an interpopulation comparison of sedentary groups, including Indians, Israelis, Americans and Swedes. In particular, it was noted that sedentary ethnic groups living in India had the lowest maximal oxygen uptake scores when compared with other populations. It was suggested that the lower maximal oxygen uptake scores were probably due to the low level of participation in sport and that such factors as nutritional status, environment and heredity may also have been responsible.

The implications of genetically inherited fitness levels may be pertinent in an educational context. It could mean that expatriated ethnic groups undertaking physical education programmes in schools and colleges have an inherent physiological disadvantage. The traditional physical education curriculum comprises of sports and team games which require a satisfactory level of endurance fitness in conjunction with the need to acquire specific skills. The acquisition of such skills would be enhanced if the individual had sufficient physiological capacity to enable persistent practice.

The purpose of this investigation was to compare the levels of endurance fitness (as indicated by predicted maximal oxygen uptake levels) of two groups of male students - Anglo-Saxon students and first generation, expatriated Indian Students (none of whom was highly active in any particular sport).

\section{METHODS}

The subjects were 32 indigenous, male Anglo-Saxon college students (age range 16-18 years) and 27 expatriated, first generation, Indian male college students (age range 1623 years). All subjects were full time students studying mechanical or electrical engineering at a college of commerce and technology. A pre-test questionnaire of the subjects' activity levels revealed a range from sedentary to moderately active.

Maximal oxygen uptake was estimated by an indirect method based on the linear relationship between heart rate, oxygen uptake and workload at submaximal levels. Subjects worked at a range $50 \mathrm{w}, 100 \mathrm{w}$ and $150 \mathrm{w}$ on a Tunturi cycle ergometer for 5 minutes at each workload. The seat 
height was adjusted for each subject so that the knee was slightly flexed with the ball of the foot resting on the pedal at the lowest point in revolution. Prior to each test the ergometer was calibrated by suspending a known weight from the brake stirrup. Steady state heart rate was recorded in the 5th minute. If the steady state heart rate at $150 \mathrm{w}$ was less than 145 beats per minute the loading was increased to $175 w$ or $200 w$ for a further 5 minutes. Dotson and Caprarola (1984) observed that a heart rate of 145 beats per minute allows for a good estimate of maximal oxygen uptake. Heart rate was displayed on a Tunturi Cardiotester. Maximal oxygen uptake was predicted according to the method described by Åstrand and Rodahl (1977).

Harpenden skinfold calipers were used to determine skinfolds over the biceps, triceps (midway between the olecranon and acromion), at the inferior angle of the scapula and over the iliac crest. A minimum of two trials was taken to ensure an average of less than $1 \mathrm{~mm}$ discrepancy. The summation of the four readings gave the percentage body fat using the table derived by Durnin and Womersley (1974).

A Takeikiki Kogyo grip dynamometer was used to give an additional indication of strength. A maximum force was exerted for 2-3 seconds by the dominant hand with the dynamometer held by the side, but clear of the thigh. This procedure was repeated 3 times. Each trial was separated by 3 minutes. The mean of 3 trials was then calculated.

\section{RESULTS}

The results of the investigation are presented in Table I. Mean body weight of the Anglo-Saxon group (65.4 kg \pm 8.9 ) was significantly higher $(p<0.05)$ than the Indian group $(60.8 \mathrm{~kg} \pm 6.2)$. The higher body weight of the Anglo-Saxon group was due to a higher absolute lean body weight and fat weight, although there was no actual difference in the proportions of these two components between the two groups. The difference in lean body weight did not elicit a corresponding difference in strength.

TABLE I

Group comparisons

\begin{tabular}{|c|c|c|c|c|c|c|}
\hline & \multicolumn{2}{|c|}{$\begin{array}{l}\text { Anglo- } \\
\text { Saxon } \\
(n=32)\end{array}$} & \multicolumn{2}{|c|}{$\begin{array}{l}\text { Indian } \\
(\mathrm{n}=27)\end{array}$} & \multirow[t]{2}{*}{$\mathbf{t}$} & \multirow[t]{2}{*}{$\mathbf{p}$} \\
\hline & $\bar{x}$ & s & $\bar{x}$ & $\mathbf{s}$ & & \\
\hline Age (yrs) & \multicolumn{2}{|c|}{$17.5 \pm 0.6$} & \multicolumn{2}{|c|}{$17.8 \pm 3.8$} & 0.3 & NS \\
\hline Weight (kg) & \multicolumn{2}{|c|}{$65.5 \pm 8.9$} & \multicolumn{2}{|c|}{$60.9 \pm 6.2$} & 2.2 & $<0.05$ \\
\hline Body Fat $\%$ & \multicolumn{2}{|c|}{$14.5 \pm 4.1$} & \multicolumn{2}{|c|}{$15.2 \pm 3.8$} & 1.4 & NS \\
\hline Lean body mass (kg) & \multicolumn{2}{|c|}{$55.9 \pm 7.0$} & \multicolumn{2}{|c|}{$51.6 \pm 4.5$} & 2.8 & $<0.01$ \\
\hline Strength (kg) & \multicolumn{2}{|c|}{$47.4 \pm 6.0$} & \multicolumn{2}{|c|}{$46.4 \pm 4.8$} & 0.4 & NS \\
\hline \multicolumn{7}{|l|}{ Maximum oxygen uptake } \\
\hline $\mathrm{ml} \mathrm{kg}^{-1} \mathrm{~min}^{-1}$ & \multicolumn{2}{|c|}{$49.1 \pm 6.9$} & \multicolumn{2}{|c|}{$43.2 \pm 7.9$} & 3.1 & $<0.01$ \\
\hline${ }^{*} \mathrm{ml} . \mathrm{ffkg}^{-1} \mathrm{~min}^{-1}$ & \multicolumn{2}{|c|}{$57.7 \pm 9.3$} & \multicolumn{2}{|c|}{$50.5 \pm 8.4$} & 3.6 & $<0.01$ \\
\hline
\end{tabular}

Table t (57df) $0.05=2.03$

$$
0.01=2.66
$$

* $\mathrm{ml} . \mathrm{ffkg}^{-1} \mathrm{~min}^{-1}=\mathrm{ml}$ of oxygen per $\mathrm{kg}$ of fat free body mass per minute

The relative maximal oxygen uptake for the Anglo-Saxon group was similar to the values observed by Williamson and Hamley (1984) on 38 male air crew (ages 20-29) using similar testing techniques. The absolute maximal oxygen uptake differences of $0.71 \mathrm{I} . \mathrm{min}^{-1}$ between the two groups was significant $(p<0.01)$. This higher absolute level of oxygen uptake could be related to the higher absolute lean muscle mass of the Anglo-Saxon group. However, when the absolute levels were converted relative to total body weight

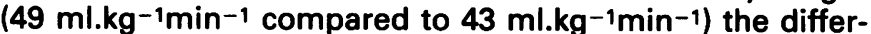
ence remained $(p<0.01)$. There was also a significant difference $(p<0.01)$ in oxygen consumption relative to lean body mass $\left(57.7 \mathrm{ml}^{\mathrm{ffkg}}{ }^{-1} \mathrm{~min}^{-1}\right.$ compared with 50.5 $\left.\mathrm{ml}^{.} \mathrm{ffg}^{-1} \mathrm{~min}^{-1}\right)$.

\section{DISCUSSION}

The findings showed that the absolute and relative predicted maximal oxygen uptake of the Indian group was significantly lower than the Anglo-Saxon group. Although the relative values of both groups may be classed as 'average' (Åstrand, 1970), there does appear to be a considerable disparity in the endurance fitness between the two groups.

One would expect a higher absolute maximal oxygen uptake with increased lean body mass, as was evident in this study, but a correction for total body weight (ml. $\left.\mathrm{kg}^{-1} \mathrm{~min}^{-1}\right)$ still revealed differences in oxygen uptake. As there was no significant difference in the proportion of body fat between the two groups, the lower relative oxygen consumption of the Indian group could not be attributed to this factor. Analysis revealed that the oxygen consumption per unit of lean body mass was also significantly lower in the Indian group.

Although the Indians of this study have been shown to have lower endurance levels than the indigenous sample, one must be cautious in the interpretation and application of these findings. Predictive submaximal tests of maximal oxygen uptake will only 'estimate' the maximal value, with the error between predicted and measured oxygen consumption sometimes reaching 25 percent for some subjects (Davies, 1968). It is acknowledged, however, that these types of tests are better predictors for subjects falling within the 'average' maximum oxygen uptake category (MacDougall et al, 1984) which describes the sample used in this study.

Although it is acknowledged that firm conclusions remain elusive, the investigation may have indicated a possible need for further research into the fitness levels of ethnic communities involved in physical activity programmes in this country. If the findings are substantiated, the physical educator/programme leader should perhaps modify performance expectations of similar sedentary groups. This would allow for more appropriate and individualised programmes of endurance fitness to be implemented.

\section{References}

Astrand, P. O., 1970. Work Tests with the Bicycle Ergometer. MonarkCrescent. Varberg, Sweden.

Astrand, P. O. and Rodahl, K., 1977. Textbook of Work Physiology. McGrawHill, London.

Davies, C. T. M., 1968 "Limitations to the prediction of maximal oxygen intake from cardiac frequency measurements". J.Appl.Physiol. 24: 700-706.

Dotson, C. O. and Caprarola, M. A., 1984 "Maximal oxygen intake estimated from submaximal heart rate". Brit.J.Sports Med. 18: 191-194.

Durnin, J. V. G. A. and Womersley, J., 1974 "Body fat assessed from total body density and its estimation from skinfold thickness: measurements on 481 men and women aged 16-72 years". Brit.J.Nutr. 32: 77-162.

Fox, E. L. and Mathews, D. K., 1981. The Physiological Basis of Physical Education and Athletics. Saunders, London.

Klissouras, V., 1971 "Heritability of adaptive variation". J.Appl.Physiol. 31: 338-334.

Klissouras, V., Pirnay, F. and Petit, J., 1973 “Adaptations to maximal effort: genetics and age". J.Appl.Physiol. 35: 228-293.

MacDougall, J. D., Wenger, H. A. and Green, H. J. (eds.), 1984. Physiological Testing of the Elite Athlete. Canadian Association of Sports Sciences. Mutual Press.

Verma, S. K., Sidhu, L. S. and Kansal, D. K., 1979 "Aerobic work capacity in young sedentary men and active athletes in India". Brit.J.Sports Med. 13: 98-102.

Williamson, W. M. and Hamley, E. J., 1984 "Fitness and health measurement in air crew". Brit.J.Sports Med. 18: 110-115. 